\title{
Características agronômicas e teor de óleo da canola em função da época de semeadura
}

\author{
Milciades A. Melgarejo. A. ${ }^{1}$, José B. Duarte Júnior ${ }^{2}$, Antonio C. T. da Costa ${ }^{3}$, \\ Éder J. Mezzalira ${ }^{4}$, Andre L. Piva ${ }^{5}$ \& Anderson Santin ${ }^{6}$ \\ ${ }^{1}$ PPGA/CCA/UNIOESTE. Marechal Cândido Rondon, PR. E-mail: milciadesmelgarejo1@gmail.com (Autor correspondente) \\ ${ }^{2}$ CCA/UNIOESTE. Marechal Cândido Rondon, PR. E-mail: jose.junior6@unioeste.br \\ ${ }^{3}$ CCA/UNIOESTE. Marechal Cândido Rondon, PR. E-mail: antonio.costa2@unioeste.br \\ ${ }^{4}$ PPGA/CCA/UNIOESTE. Marechal Cândido Rondon, PR. E-mail: eder.mezzalira@gmail.com \\ ${ }^{5}$ PPGA/CCA/UNIOESTE. Marechal Cândido Rondon, PR. E-mail: andrepv8@gmail.com \\ ${ }^{6}$ PPGA/CCA/UNIOESTE. Marechal Cândido Rondon, PR. E-mail: santin-8@hotmail.com
}

\section{Palavras-chave:}

Brassica napus L. var oleifera produtividade

população

\section{R E S U M O}

Propôs-se, com este trabalho, avaliar a influência das diferentes épocas de semeadura sobre a população de plantas, produtividade e teor de óleo da canola (Brassica napus L.) na safra de 2012. Utilizou-se o delineamento experimental em blocos casualizados, em esquema de parcelas subdivididas 7 x 2, sendo sete épocas de semeadura: 24/03/12; 07/04/12; 21/04/12; 05/05/12; 19/05/12; 02/06/12 e 16/06/12 e dois híbridos: Hyola 61 e Hyola 433. As produtividades e os teores de óleo foram semelhantes entre os híbridos, com médias de $1058 \mathrm{~kg} \mathrm{ha}^{-1}$ e $38.2 \%$, respectivamente. O avanço nas épocas de semeadura reduziu a produtividade e o teor de óleo. Para obtenção de maiores rendimentos de grãos com maior conteúdo de óleo nos grãos, recomenda-se a semeadura dos híbridos Hyola 61 e Hyola 433 até 20/04, especialmente se houver expectativa de baixas precipitações no período do inverno.

\section{Key words:}

Brassica napus L. var oleifera yield population

\section{Agronomic characteristics and oil content of rapeseed as a function of sown date}

\begin{abstract}
A B S T R A C T
The aim of this study was to evaluate the influence of different sowing dates on plant population, yield and oil content of rapeseed (Brassica napus L.) crop in 2012. A completely randomized block design in a split-plot $2 \times 7$ was used with seven sowing dates: 24/03/12, 07/04/12, 21/04/12, 05/05/12, 19/05/12, 02/06/12 and 16/06/12 and two hybrids: Hyola 61 and Hyola 433. The yield and oil content were similar among treatments, on average 1058 $\mathrm{kg} \mathrm{ha}^{-1}$ and $38.2 \%$, respectively. The advancement in sowing times reduced productivity and oil content. To obtain higher grain yields, with higher oil content in the grain, it is recommended to sow hybrids Hyola 61 and Hyola 433 until 20/04, especially if there is expectation of low rainfall during the winter period.
\end{abstract}

\section{INTRODUÇÃO}

A canola (Brassica napus) foi desenvolvida através do melhoramento genético da colza, uma espécie oleaginosa, pertencente à família Brassicae (crucíferas) a partir da qual foram selecionados cultivares com teores de glucosinolatos reduzidos e ácido erúcico, nocivos ao organismo animal (Figueiredo et al., 2003).

A canola vem-se ressaltando como importante espécie alternativa produtora de grãos no período de estação fria do ano nas condições do sul do Brasil (Krüger et al., 2011). Esta cultura é sumamente significativa economicamente, destacando-se como a terceira oleaginosa mais produzida no mundo, em decorrência da qualidade e do conteúdo de óleo dos grãos, além de elevada quantidade de proteína (Tomm, 2007).

O cultivo de canola no período do inverno possui grande valor socioeconômico por oportunizar a produção de grãos e óleos vegetais neste período, somando sua produção às culturas de verão e otimizando os meios de produção (terra, equipamentos e pessoas) uma vez que o cultivo do trigo não se tem tornado atraente para os produtores. Da mesma forma, a canola se encaixa nos sistemas de rotação de culturas para produção de grãos podendo contribuir com a redução de problemas fitossanitários de leguminosas, como a soja e o feijão, e das gramíneas, como o milho, trigo e outros cereais (Tomm et al., 2009). Pode, ainda, ser utilizada como cobertura vegetal do solo no período de inverno, no sul do Brasil. No Brasil se cultiva apenas canola de primavera, da espécie Brassica napus L. var. oleifera porém seu cultivo tardio no inverno poderia contribuir para otimizar ainda mais a utilização dos recursos agrícolas criando-se mais uma oportunidade de renda para os agricultores.

Até o presente momento os estudos relacionados com a cultura da canola dizem respeito a variedades ou híbridos 
provenientes de outros países que apresentam comportamento diferente dos genótipos utilizados atualmente em escala comercial no Brasil (Dalmago et al., 2010).

A região Oeste do Paraná é a que mais tem investido no cultivo desta oleagionsa sendo responsável por $37 \%$ da produção do estado. O setor depende, também, de sementes importadas para o cultivo e o manejo haja vista que vêm sendo testadas e desenvolvidas pelos próprios produtores da região (Oliveira, 2011). Entretanto, a canola ainda é pouco estudada na região oeste do Paraná tornando-se necessária a condução de maiores pesquisas com a cultura tendo em vista a produção de híbridos mais adaptados ao clima da região e também a melhor época para a realização do seu cultivo. Neste sentido, o presente trabalho teve, como objetivo, avaliar o desempenho agronômico e o potencial fisiológico das sementes de dois híbridos de canola (Hyola 433 e Hyola 61) em função de diferentes épocas de semeadura na região de Marechal Cândido Rondon, oeste do Paraná.

\section{Material e Métodos}

O experimento foi realizado a campo, durante o período de 24/03/12 a 15/12/12, na Fazenda Experimental Antônio Carlos dos Santos Pessoa, da Universidade Estadual do Oeste do Paraná (UNIOESTE) localizada no município de Marechal Cândido Rondon, Região Oeste do Estado do Paraná.

O município de Marechal Cândido Rondon está situado a $24^{\circ} 33^{\prime} 40^{\prime \prime}$ de latitude Sul e 54 04' $12^{\prime \prime}$ de longitude Oeste, com altitude de $420 \mathrm{~m}$ acima do nível do mar e relevo com leve declividade. O clima, segundo a classificação de Köppen, é Cfa, com verões quentes, geadas pouco frequentes e tendência à concentração de chuvas nos meses de verão, sem estação seca definida, caracterizando-se como região subtropical. Apresenta temperatura média inferior a $18{ }^{\circ} \mathrm{C}$ (mesotérmico) no mês mais frio e temperatura média acima de $22{ }^{\circ} \mathrm{C}$ no mês mais quente. A precipitação anual média está em torno de $1.840 \mathrm{~mm}$ (IAPAR, 2012). Durante a condução do experimento os dados meteorológicos locais foram coletados e registrados na Estação Meteorológica Automática localizada na estação experimental da UNIOESTE e estão dispostos nas Figuras 1.

O solo da área experimental foi classificado como LVe-1 Latossolo Vermelho Eutroférrico, profundo, de textura argilosa (Bhering \& Santos, 2008). O solo foi caracterizado mediante análises química e física, amostrando-se verticalmente a camada de $0-10,11-20$ e $21-40 \mathrm{~cm}$ de profundidade apresentando, fisicamente, $6 \%$ de areia, $4 \%$ de silte e $89 \%$ de argila pelo método do decímetro de Boyoucos. As análises foram realizadas pelo Laboratório de Química Agrícola Ambiental da UNIOESTE. O resultado da análise química do solo de toda a área, anterior à instalação do experimento, evidenciou valores de $\mathrm{P}=8,65$ (mg $\left.\mathrm{dm}^{-3}\right) ;$ M. O. $=25,51\left(\mathrm{~g} \mathrm{dm}^{-3}\right) ; \mathrm{pH}\left(\mathrm{CaCl}_{2}\right)=4,75 ; \mathrm{H}+\mathrm{Al}=5,35$ $\left(\mathrm{cmol}_{\mathrm{c}} \mathrm{dm}^{-3}\right) ; \mathrm{Al}^{3+}=0,31\left(\mathrm{cmol} \mathrm{dm}^{-3}\right) ; \mathrm{K}^{+}=0,42 ; \mathrm{Ca}^{+2}=5,54$ $\left(\mathrm{cmol} \mathrm{dm}^{-3}\right) ; \mathrm{Mg}^{+2}=1,48\left(\mathrm{cmol} \mathrm{dm}^{-3}\right) ;$ S.B. = 7,44 $\left(\mathrm{cmol} \mathrm{dm}^{-3}\right)$; C.T.C. $=12,79\left(\mathrm{cmol}_{\mathrm{c}} \mathrm{dm}^{-3}\right) ; \mathrm{V}=58,42(\%)$ e $\mathrm{Al}=4,17$ (\%).

$\mathrm{O}$ delineamento experimental utilizado foi em blocos casualizados, em esquema de parcelas subdivididas $7 \mathrm{x}$ 2, com quatro repetições. Nas parcelas foram alocadas as
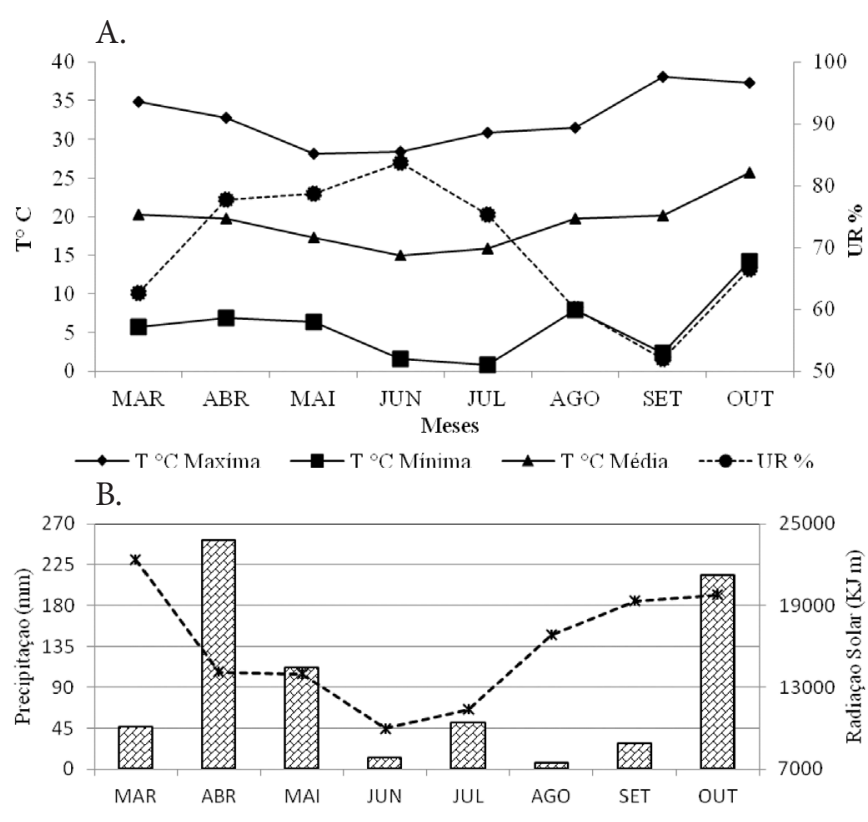

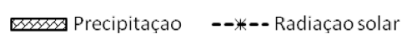

Figura 1. A) Umidade relativa (\%), temperatura máxima, mínima e média. B) Precipitação e radiação solar ocorridos na área experimental durante o período de março a outubro/2012

sete épocas de semeadura $(24 / 03 / 12 ; 07 / 04 / 12 ; 21 / 04 / 12$; $05 / 05 / 12 ; 19 / 05 / 12 ; 02 / 06 / 12$ e 16/06/12 equivalente a 0,14 , $28,42,56,70$ e 84 respectivamente nas equações) mantendo-se intervalos regulares de 14 dias enquanto nas subparcelas foram distribuídos os dois híbridos de canola estudados, Hyola 61 e Hyola 433, constituindo 14 tratamentos.

A área experimental se encontrava sob o sistema de semeadura direta desde 2009, sob a sucessão aveia/milho/aveia/ soja. O experimento ocupou uma área experimental total de $1.311 \mathrm{~m}^{2}$, sendo que cada subparcela possuía $13,5 \mathrm{~m}^{2}$. A parcela ou unidade experimental apresentava as seguintes dimensões: 2,7 $\mathrm{m}$ de largura e $5 \mathrm{~m}$ de comprimento contendo 6 linhas com espaçamento de $0,45 \mathrm{~m}$, entre si, com área útil central de $3,6 \mathrm{~m}^{2}$.

Após a seleção da área experimental os quatro blocos foram dispostos de forma aleatória e transversa ao gradiente de argila do terreno, determinado pela análise textural do solo. Mantevese um espaçamento entre blocos de $1 \mathrm{~m}$ e entre parcelas de $0,5 \mathrm{~m}$.

Os híbridos utilizados neste experimento foram Hyola 61 e Hyola 433. O híbrido Hyola 61 possui resistência poligênica à canela-preta, excelente desempenho tanto sob deficiência hídrica como sob frios intensos. Com características de ciclo médio de 123 a 155 dias da emergência a maturação e ainda apresenta grande estabilidade de rendimento quando cultivado em condições variadas (Tomm et al., 2009).

Já Hyola 433 é um híbrido de ciclo curto indicado para os solos de elevada fertilidade. Este genótipo apresenta elevada exigência de condições ambientais favoráveis, especialmente solos de alta fertilidade, para expressar seu elevado potencial, sendo recomendado evitar a semeadura em ambientes com limitações de umidade e de fertilidade de solo (Tomm et al., 2009). 
Para a adubação do solo na época de semeadura foram utilizados $200 \mathrm{~kg} \mathrm{ha}^{-1}$ do formulado 10-20-20 aplicados na linha de plantio. Em cobertura foram aplicados $405 \mathrm{~kg} \mathrm{ha}^{-1}$ de Sulfato de amônio no estádio $B_{4}$, quando as plantas apresentavam quatro folhas verdadeiras para só então suprir as demandas de nitrogênio e enxofre. A adubação baseou-se nas interpretações da análise química do solo de acordo com as recomendações sugeridas pela EMBRAPA (Tomm et al., 2009).

O manejo de plantas daninhas foi feito por meio de capinas manuais realizadas sempre que necessário, ao longo da condução do experimento. Durante a condução do experimento não se constatou o aparecimento de doenças ou insetos pragas. O experimento foi conduzido sem sistema de irrigação.

As sementes foram provenientes da Embrapa Trigo, previamente tratadas e testadas, apresentando poder germinativo (PG) acima de $90 \%$ para todas as épocas e híbridos utilizados.

Para a implantação da cultura da canola adotou-se o sistema de semeadura direta, com início das semeaduras em 24/03/12. Antes de cada semeadura referente a cada época era realizada capina manual das parcelas com posterior distribuição do fertilizante em profundidade de $7-8 \mathrm{~cm}$ e das sementes de canola em profundidade de $1-2 \mathrm{~cm}$. Adotou-se o espaçamento entre linhas de $45 \mathrm{~cm}$ e a densidade de semeadura de 22 sementes por metro linear.

A colheita manual das plantas de canola da área experimental foi realizada respeitando-se o ciclo das plantas enquanto as mesmas se encontravam no estádio de maturação fisiológica. Foram colhidas todas as plantas da área útil de cada parcela quando aproximadamente $50 \%$ das plantas se encontravam no estádio fenológico $G_{5}$, ou seja, apresentavam alteração na coloração dos grãos. As plantas colhidas foram submetidas à secagem ao sol durante 5 dias.

O número de plantas por área foi avaliado por ocasião da colheita, por meio da contagem de todas as plantas da área útil.

Para avaliar a produtividade de cada parcela foi realizada a colheita de todas as plantas da área útil no estádio fenológico $\mathrm{G}_{5}$ as quais foram trilhadas retirando-se as impurezas. Utilizouse um determinador de umidade para padronizar a umidade dos grãos de cada parcela de acordo com a equação abaixo e se determinando assim a produtividade.

O teor de óleo nas sementes foi determinado no Laboratório de Nutrição Animal da UNIOESTE; para tal, as amostras uniformes de sementes foram submetidas à secagem em estufa com ventilação forçada de ar sob $65^{\circ} \mathrm{C}$ durante $48 \mathrm{~h}$ visando à uniformização da umidade. Após a secagem procedeu-se à moagem das sementes com casca e à determinação do teor de óleo. O farelo das sementes foi embalado em cartuchos de papel, na quantidade de $2 \mathrm{~g}$ por cartucho, em duplicata por unidade experimental. Na extração foi adotada a metodologia descrita em IUPAC (1979), utilizando-se o sistema soxhlet e o solvente extrator éter de petróleo e o tempo de extração de $6 \mathrm{~h}$. Após a extração os cartuchos foram mantidos em estufa a $60^{\circ} \mathrm{C}$ por 24 h para completa evaporação do éter de petróleo.

As variáveis qualitativas foram submetidas à análise de variância aplicando-se o teste $\mathrm{F}$ em nível de 0,05 de probabilidade; já para as variáveis quantitativas os dados foram submetidos à análise de regressão.

\section{Resultados e Discussão}

O número de plantas por área obtido no experimento não apresentou valores diferentes significativamente $(\mathrm{P} \leq 0,05)$ para a interação híbrido x épocas de semeadura. Desta forma, o número médio de plantas por área foi de 252.500 plantas por hectare inferior, portanto, ao esperado, que era de 488.888 plantas ha ${ }^{-1}$ devido, possivelmente, à ocorrência de estresse por déficit hídrico, em especial nas últimas épocas de semeadura. Tomm et al. (2009) recomendam 40 plantas $\mathrm{m}^{-2}$ uniformemente distribuídas. A uniformidade da população de plantas permite melhor potencial de rendimento dos grãos. Assim, standes similares ( 45 plantas $\mathrm{m}^{2}$ ) também foram recomendados por Chavarria et al. (2011).

Não foram encontradas diferenças estatísticas de produtividade entre os híbridos Hyola 61 e Hyola 433 no presente trabalho cuja média foi de $1058 \mathrm{~kg} \mathrm{ha}^{-1}$. No entanto, Estevez (2012) encontrou, avaliando as mesmas características com os mesmos híbridos e na mesma região, diferenças estatísticas na produtividade entre híbridos sendo o de maior produtividade o híbrido Hyola 433, com média de produtividade de 1359 $\mathrm{kg} \mathrm{ha}^{-1}$ e o Hyola $61 \mathrm{com}$ média de $1222 \mathrm{~kg} \mathrm{ha}^{-1}$. Tomm et al. (2009) observaram, avaliando a produtividade de dois híbridos (Hyola 43 e Hyola 60) de canola semeados em diferentes épocas durante o ano no município de Três de Maio - RS, que as maiores produtividades de grãos foram obtidas nos meses de maio e abril para os híbridos Hyola 43 e Hyola 60, respectivamente.

Observa-se com frequência, nas diversas espécies oleaginosas, uma discrepância no rendimento dos grãos cujas fontes de variação podem ser originadas do genótipo, densidade de plantas, adubação nitrogenada (Krüger et al., 2011) e condições climáticas. As baixas precipitações durante o experimento do presente estudo (Figura 1B) limitaram a expressão do potencial produtivo do genótipo Hyola 433, que é exigente em condições ambientais, como umidade do solo fazendo com que se equiparasse ao híbrido Hyola 61 menos exigente (Tomm et al., 2009).

A produtividade dos híbridos de canola foi afetada significativamente apenas pelas épocas de semeadura em resposta às quais se ajustou à regressão polinomial de segundo grau. Para esta variável a máxima produtividade foi obtida na data estimada de 24/03, com posterior redução (Figura 2). A redução na produtividade da canola semeada em datas posteriores a 24/03 é devida às condições climáticas, caracterizadas por uma redução no volume de precipitações após abril com aumento da radiação solar e das temperaturas após junho (Figuras 1 e 2) o que afetou negativamente a produtividade dos dois híbridos estudados.

$\mathrm{O}$ valor de produtividade por unidade de área mais expressiva e referente à primeira época de semeadura, enquanto que a menor produtividade por área foi obtida na última época de semeadura (Figura 2). Semelhantemente Souza et al. (2010) relataram, avaliando o comportamento fenológico da canola no Brejo Paraibano, que dentre os 12 cultivares estudados os que apresentaram resultados satisfatórios quanto à produtividade foram os de ciclo precoce. 


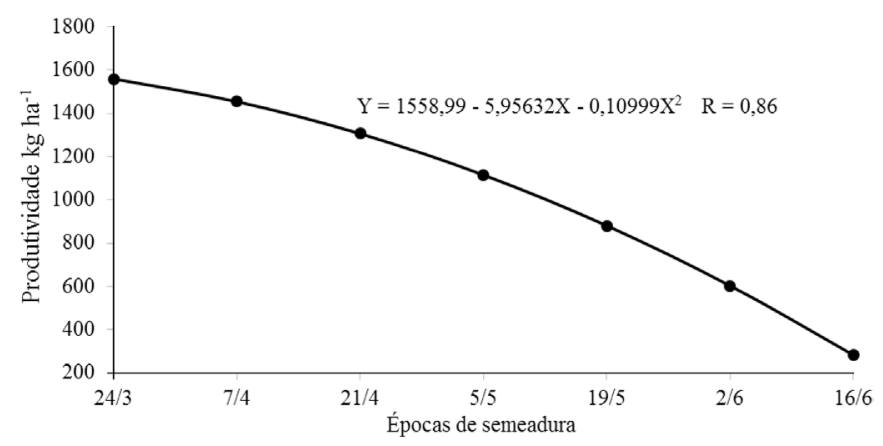

* 24/3, 7/4, 21/4, 5/5, 19/5, 2/6 e 16/6 equivalem no $X$ da equação a 0, 14, 28, 42, 56, 70 e 84 respectivamente

** Significativo a 0,01 de probabilidade pelo teste $\mathrm{t}$

Figura 2. Produtividade de canola em diferentes épocas de semeadura, em Marechal Cândido RondonPR, durante a safra 2012

Em estudo com colza, o período crítico para a determinação do rendimento da cultura ocorre desde o início da floração até o final do período de fixação de grãos (Champolivier \& Merrien, 1996) e McGregor (1981) indicaram que temperaturas maiores que $27^{\circ} \mathrm{C}$ durante a floração ocasionaram redução na fertilidade das flores por esterilidade dos ovários, infertilidade do pólen e aborto de síliquas.

Sidlauskas \& Bernotas (2003) mencionam que um aumento no período vegetativo combinado com alta precipitação, favorece um incremento no rendimento enquanto que um aumento na temperatura tem efeito negativo ao incrementar as unidades calóricas Rao \& Mandham (1991) demonstraram que Brassica napus estabelecida em um ambiente com temperatura amena produziu rendimentos mais altos do que quando cresceu em ambientes com temperaturas altas. Temperaturas amenas e umidade adequada favorecem o desenvolvimento, o peso e o teor de óleo dos grãos de brássicas (Sidlauskas \& Bernotas, 2003; Morales et al., 2006).

Quanto ao teor de óleo nos grãos, houve significância das épocas de semeadura $(P<0,05)$ sem efeitos significativos das demais fontes de variação estudadas $(P>0,05)$. Ocorreu um ajuste quadrático do teor de óleo dos grãos ao longo das épocas de semeadura, com aumento do teor de óleo até a época de semeadura estimada em 05/04 (Figura 3). Semeaduras posteriores proporcionaram menor teor de óleo nos grãos; esses resultados foram observados devido às condições climáticas de vez que as precipitações limitadas observadas após o mês de abril, limitaram o desenvolvimento da cultura com consequente efeito negativo no teor de óleo dos grãos (Figura 2).

Segundo Larrosa (2009) a redução do teor de óleo estaria relacionada inversamente com a temperatura média durante o período de enchimento dos grãos afirmando que valores superiores a $21{ }^{\circ} \mathrm{C}$ geram quedas bruscas no conteúdo de óleo dos grãos, além de grãos deformados, aparentemente produzidos por estresse térmico severo.

O consumo vem aumentando em razão da melhora da qualidade e da aceitação do óleo de canola em decorrência do seu baixo teor de gordura saturada, inferior aos dos óleos de girassol, milho e soja (Iriarte et al., 2008).

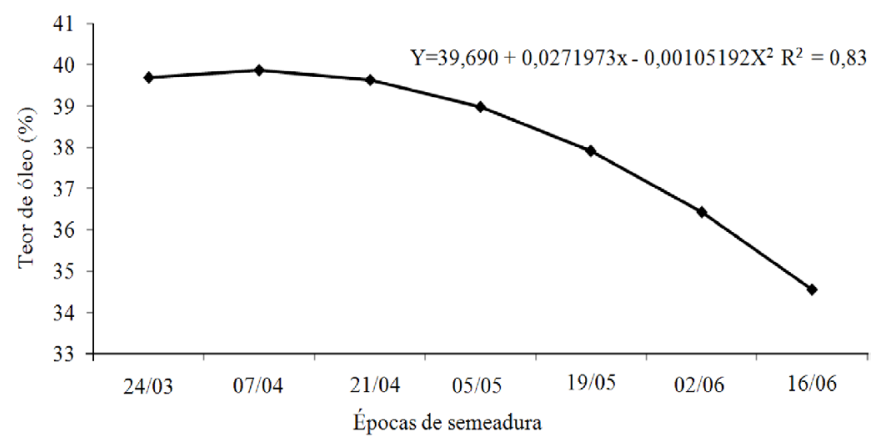

* 24/3, 7/4, 21/4, 5/5, 19/5, 2/6 e 16/6 equivalem no $X$ da equação a 0, 14, 28, 42, 56, 70 e 84 respectivamente

** Significativo a 0,01 de probabilidade pelo teste $\mathrm{t}$

Figura 3. Teor de óleo (\%) de canola em diferentes épocas de semeadura em Marechal Cândido Rondon, durante a safra 2012

A canola é uma planta muito exigente com relação à disponibilidade de recursos do ambiente, necessitando de condições específicas para cada estádio fenológico da planta. A influência da época de semeadura no enchimento de grãos é justificada devido ao condicionamento do desenvolvimento da cultura em condições propícias ou não para a produção ou síntese de proteínas e/ou óleos nos grãos da canola. Assim, é importante lembrar que, ao ocorrer uma redução da radiação fotossinteticamente ativa, acarreta em diminuição do teor de óleo (Aguirrezábal et al., 2003) e quando ocorre aumento do número de horas de radiação direta, durante a fase de enchimento de grãos.

Portanto, o aumento do número de horas de radiação normalmente está associado ao incremento de temperatura e ao maior gasto energético (Krüger et al., 2011) o que justifica a redução no teor de óleo relacionada às últimas épocas de semeadura, com os maiores valores de temperatura e radiação solar direta (Figuras 1 e 2).

Variações no teor de óleo em decorrência das épocas de semeadura também foram relatadas por outros autores em diversas culturas oleaginosas. Thomaz et al. (2012) por exemplo, observaram, durante experimento na região Centro-Sul do Paraná, que o teor de óleo na cultura do girassol é influenciado pela época de semeadura. Em estudos realizados por Lelis et al. (2010) com a cultura da soja em Minas Gerais foi possível observar interação entre a época de semeadura, genótipo e teor de óleo. Champolivier \& Merrien (1996) encontraram que o baixo teor de óleo nos grãos de canola está relacionado com déficit hídrico.

O teor médio de óleo obtido durante o período experimental foi de 38,2\%; valor médio esperado no Brasil segundo Tomm et al. (2009). O valor máximo obtido para esta variável foi de $39,9 \%$ na segunda época e mínimo de $34,55 \%$ na sétima época. Os teores máximos e mínimos são, respectivamente, $4,3 \%$ superiores e 9,5\% inferiores à média do teor de óleo obtida durante o período avaliado (Figura 3 )

Gunasekera et al. (2006) estudaram o efeito do genótipo e ambiente e sua interação sobre o teor de óleo na canola em ambientes mediterrâneos de Austrália, encontrando que o ambiente exerce papel fundamental na determinação do teor de óleo. 


\section{Conclusões}

1. Para os dois híbridos estudados obteve-se, na primeira época de semeadura, a maior produtividade.

2. Para a variável produtividade não foram observadas diferenças entre híbridos, resultando uma média de $1058,5 \mathrm{~kg} \mathrm{ha}^{-1}$.

3. O teor médio de óleo obtido durante o período experimental foi de $38,2 \%$.

\section{Agradecimentos}

Os autores agradecem à Universidade Estadual do Oeste do Paraná (UNIOESTE), ao Programa de Pós-graduação em Agronomia (PPGA) à Empresa Brasileira de Pesquisa Agropecuária (EMBRAPA), ao Centro Nacional de Pesquisa do Trigo (CNPT) e ao Parque Tecnológico de Itaipu (PTI) pela concessão da bolsa de estudo.

\section{Literatura Citada}

Aguirrezábal, L. A. N.; Lavaud, Y.; Dosio, G. A. A.; Izquierdo, N. G.; Andrade, F. H.; Gonzalez, L.M. Intercepted solar radiation during seed filling determines sunflower weight per seed and oil concentration. Crops Science, v.43, p.152-161.2003.

Bhering, S. B.; Santos, H. G. Mapa de solos do estado do Paraná. Legenda atualizada. Rio de Janeiro: Embrapa Florestas: Embrapa Solos/Instituto Agronômico do Paraná, 2008. 74p.

Champolivier, L.; A. Merrien. Effects of water stress applied at different growth stages to Brassica napus L. var. oleifera on yield, yield components and seed quality. European Journal of Agronomy, v.5, p.153-160.1996.

Chavarria, G.; Tomm, G. O.; Muller, A.; Mendonça, H. F.; Mello, N.; Betto, M. S. Índice de área foliar em canola cultivada sob variações de espaçamento e de densidade de semeadura. Ciência Rural, v.41, p.2084-2089, 2011.

Dalmago, G. A.; Cunha, G. R. Da; Santi, A.; Pires, J. L. F.; Müller, A. L.; Bolis, L. M. Aclimatação ao frio e dano por geada em canola. Pesquisa Agropecuária Brasileira, v.45, p.933-943, 2010.

Estevez, R. Caracteristicas agronômicas e produção de óleo de cultivares de canola em diferentes épocas de semeadura. Marechal Cândido Rondon: UNIOESTE, 2012. 55p. Dissertação Mestrado

Figueiredo, D.; Murakami, A. E.; Pereira, M. A.; Furlan., A. C.; Toral, F. L.; Desempenho e morfometria da mucosa de duodeno de frangos de corte alimentados com farelo de canola, durante o período inicial. Revista Brasileira de Zootecnia, v.32, p.1321-1329, 2003.

Gunasekera, C. P.; Martin L. D.; Siddique K. H. M.; Walton., G. $\mathrm{H}$. Genotype by environment interactions of indian mustard (Brassica juncea L.) and canola (Brassica napus L.) in Mediterranean-type environments: II. Crop growth and seed yield. European Journal of Agronomy, v.25, p.13-21, 2006.

IAPAR - Instituto Agronômico do Paraná. Cartas climáticas do Paraná. < http://www.iapar.br/modules/conteudo/conteudo. php?conteudo=11 66>. 23 Dez. 2012.
Iriarte, L. B.; Valetti, O. E.; Appella, C. Descripcíon de la planta. Cultivo de la Colza. Buenos Aires: Instituto Nacional de Tecnologia Agropecuária - INTA, 2008. 156p. http://www. inta.gov.ar/barrow/info/documentos/agricultura/ colza/ nota\% 20colza.pdf >. 20 Nov. 2013.

IUPAC - International Union of Pure and Applied Chemistry. Standard methods for the analysis of oils, fats and derivatives. Oxford: IUPAC, 1979. 1360p.

Krüger, C. A. M. B.; Silva, J. A. G. da; Medeiros, S. L. P.; Dalmago, G. A.; Sartori, C. O.; Schiavo, J. Arranjo de plantas na expressão dos componentes da produtividade de grãos de canola. Pesquisa Agropecuária Brasileira, v.46, p.14481453, 2011.

Larrosa L. Efecto de la fecha de siembra sobre los componentes del rendimiento en cultivares de colza. Entre Rios: Facultad de Ciencias Agropecuarias de la Universidad Nacional de Entre Ríos. 2009. 59p. Trabajo Final de Graduación

Lelis, M. M.; Hamawaki, O. T.; Tavares, M.; Aquino, L. A. Teor de óleo para genotipos de soja em tres epocas de semeadura. Bioscience Journal, v.26, p.602-609, 2010.

McGregor, D. I. Pattern of flower and pod development in rapeseed. Canadian Journal of Plant Science, v.61, p.275282, 1981.

Morales, A. S. M.; Franco, A. D.; Quintero, J. G.; Cano, I. G. La temperatura en la etapa reproductiva del cultivo de canola (Brassica napus L.). Agricultura Técnica em México, v.32, p.259-265, 2006.

Oliveira, R. Cultivo da canola ganha novos campos no Paraná. Paraná Online. 2011. Disponível em: http://www. parana-online.com.br/canal/rural/news $/ 304908 /$ ?noticia $=$ cultivo + da + canola + ganha + novos+campos + no+parana Acessada em: 15 novembro 2013.

Rao, M. S.; Mandham, N. J. Comparison of Chinoli (Brassica campestri) and B. Napus oilseed rape using different growth regulators, plant population densities and irrigation treatments. Journal of Agriculture Science, v.117, p.177-187, 1991.

Sidlauskas, G.; Bernotas, S. Some factors affecting seed yields of spring oilseed rape (Brassica napus L.) Agronomic. Research. v.12, p.229-243.2003.

Souza, T. A. F.; Raposo, R. W. C.; Dantas, A. J. A.; Silva, C. V.; Gomes Neto, A. D.; Santos, L.; Araújo, R. C. A.; Rodrigues, H. R. N.; Andrade, D. A.; Medeiros, D. A.; Dias, J. A.; Silva, E. S.; Lima, G. K.; Lucena, E. H. L.; Prates, C. S. F. Comportamento fenológico de genótipos de canola no brejo paraibano. In: Congresso Brasileiro de Mamona, 4 e Simposio Internacional de Oleaginosas Energeticas, 2010, Anais... Campina Grande: Embrapa Algodão. 2010. p.1230-1234.

Thomaz, G. L.; Zagonel, J.; Colasante, L. O.; Nogueira, R. R. Produção do girassol e teor de óleo nas sementes em diferentes épocas de semeadura no Centro-Sul do Paraná. Ciência Rural, v.42, p.203-208, 2012.

Tomm, G. O. Indicativos tecnológicos para produção de canola no Rio Grande do Sul. Passo Fundo: Embrapa Trigo, 2007. 32p.

Tomm, G. O.; Wietholer, S.; Dalmago C. A.; Santos H. P. Tecnologia para a produção de canola no Rio Grande do Sul. Passo Fundo: Embrapa Trigo, 2009. 41p. 